\title{
Localization of Harmonic Sources in Power System - Simulation and Laboratory Study
}

\author{
Mohammad Hasanuzzaman Shawon, Szymon Barczentewicz, Andrzej Bień, Zbigniew Hanzelka \\ Dept. of Power Electronics and Energy Control System \\ AGH University of Science and Technology, Krakow, Poland \\ mhshawon@agh.edu.pl
}

\begin{abstract}
One of the greatest challenges that Power Quality specialist are facing now a days is the application of correct method to identify the source of disturbance. This paper reports on the identification of harmonic source in power system considering different case scenarios along with simulation and laboratory test result.
\end{abstract}

Keywords-Power Quality, Voltage Distortion, Harmonics, Impedance Calculation, Disturbance Identification

\section{Introduction}

With the development of new technology different types of power quality issues are arising. One of them is the identification of poor power quality degradation sources in power system. Four types of electromagnetic disturbances are most significant from the additional cost perspective: voltage distortion, unbalance, voltage dip and voltage fluctuation [1]. The paper concerns only one of them - localization of harmonics. The most widely used tool to localize harmonic is the active power flow direction method [2]. Another group of harmonic localization method require the knowledge of the supply and customer network equivalent impedance for the considered harmonic [3]. However, measurement of impedance in power system is quite a challenging task. The problem of harmonic impedance calculation is discussed in [4]. The precision of impedance calculation have direct impact on accuracy of localization methods. The comparison of these two groups of harmonic localization method have seldom been reported in literature in the view point of both simulation and laboratory study. The objective of this paper is to test these selected methods by simulation and in laboratory environment.

\section{Methods of Identification}

In order to localize the harmonic source in a power system three methods are analyzed and tested in this paper. These methods are: active power flow method, scalar index method and method proposed by Wilkosz. These methods are chosen since active power flow is widely used in power quality recorders and belong to one group of method namely power direction based method.
On the other hand, scalar index method as well as method proposed by Wilkosz require impedance information and representing other group of localization method-impedance based method. The goal of the author's investigation is to report on the comparative result of these two distinct groups of harmonic localization methods.

\section{A. Active Power Flow Method}

According to this method, if active power for specific harmonic is positive, then supplier is considered as main harmonic contributor and vice versa. The active power for the specific harmonic order can be written as [5]:

$P_{h}=V_{h} I_{h} \cos \left(\phi_{v h}-\phi_{i h}\right)$

Where, $P_{\mathrm{h}}$ is the active power for $\mathrm{h}^{\text {th }}$ harmonic, $V_{\mathrm{h}}$ is the voltage and $I_{\mathrm{h}}$ is the current at $\mathrm{h}^{\text {th }}$ harmonic at PCC. However, this method has provided some erroneous result [6] and it is investigated by simulation approach in this paper.

\section{B. Scalar Index Method}

The power systems at the PCC is converted into a Norton or Thevenin equivalent circuit [7] as shown in Fig. 1(a,b) where $Z_{s}$ is source side impedance, $Z_{o}$ presents load side impedance. In all the equations, the complex format is been considered.

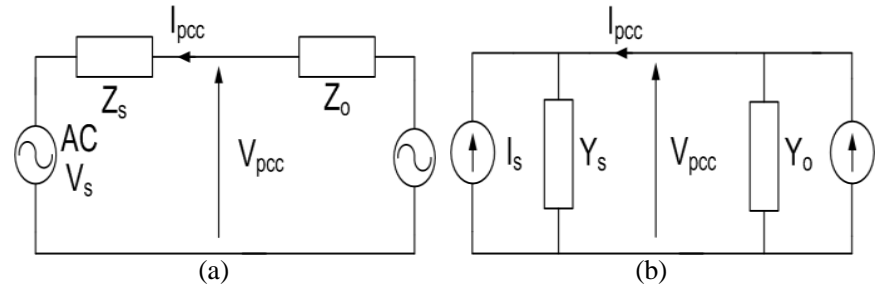

Figure 1: (a) Thevenin and (b) Norton equivalent circuit

$I_{s}=\frac{U_{P C C}}{Z_{s}}+I_{P C C} ; I_{o}=\frac{U_{P C C}}{Z_{o}}-I_{P C C}$

The contribution from the source current or voltage is

$I_{s p c c}=\frac{Z_{s}}{Z_{s}+Z_{0}} I_{s} ; V_{s p c c}=\frac{Z_{s} Z_{o}}{Z_{s}+Z_{0}} I_{s}$

Also, the contribution from the load current or voltage can be expressed by the following equations: 
$I_{\text {opcc }}=\frac{Z_{0}}{Z_{s}+Z_{0}} I_{0} ; V_{\text {opcc }}=\frac{Z_{s} Z_{0}}{Z_{s}+Z_{0}} I_{0}$

A scalar index is been proposed which employs projection of the $I_{\text {spcc }}$ (source current index) and $I_{\text {opcc }}$ (load current index) on the direction of the PCC current, represented by $I_{s f}$ and can be utilized to calculate dominating source of harmonics at PCC.

$I_{p c c}=I_{s f}+I_{o f}$

This method can provide the information of dominant harmonic source as well as individual contribution from each side. However, this method require additional algorithm to obtain impedance information and also require complex laboratory set up [8].

\section{Wilkosz Method}

In this method the localization of the dominant harmonic source is proposed using the so-called voltage rate or current rate [9].

Considering the mentioned voltage rate according to Wilkosz:

$\theta_{v}=\frac{Z-Z_{o}}{Z+Z_{S}} ; \theta_{i}=\frac{Y_{o}-Y}{Y_{s}+Y}$

For localization of dominant harmonic source the following criterion is used:

$$
\begin{aligned}
& D=D o \text { if } \theta v>1 \text { or } \theta i>1 \\
& D=N o \text { decision if } \theta v=1 \text { or } \theta i=1 \\
& D=D \text { s if } \theta v<1 \text { or } \theta i<1
\end{aligned}
$$

Wilkosz method is convenient to implement when the impedance information is known or range of impedance is known. In this papers, the case is considered only when the impedance information in known.

\section{Simulation Results}

Simulation studies of presented methods were conducted. The test system for harmonic identification is shown in fig 3 .

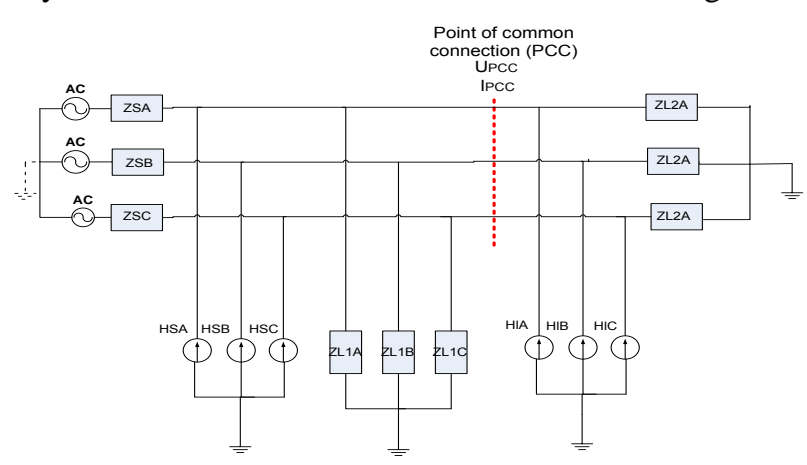

Figure 2: Test system for harmonic identification
Impedance parameters of test system, harmonic in the source side and harmonic in the load side are shown respectively in Table 1, Table 2 and Table 3.

TABLE I. IMPEDANCE PARAMETERS

\begin{tabular}{|c|c|c|}
\hline \multicolumn{2}{|c|}{ Grid side parameter seen from PCC } & Customer side parameter \\
\hline $\begin{array}{l}\text { Source internal } \\
\text { impedance, } \mathrm{Z}_{\mathrm{S}}\end{array}$ & Load impedance $1, \mathrm{Z}_{\mathrm{L} 1}$ & Load impedance $2, \mathrm{Z}_{\mathrm{L} 2}$ \\
\hline $0.5+\mathrm{j} 3.14$ & $10+\mathrm{j} 3.14$ & $10+\mathrm{j} 3.14$ \\
\hline
\end{tabular}

TABLE II. HARMONIC IN AT THE SOURCE SIDE

\begin{tabular}{|c|l|l|l|l|l|l|}
\hline $\begin{array}{c}\text { Harmonic } \\
\text { order, } \mathrm{H}_{\mathrm{n}}\end{array}$ & \multicolumn{2}{|c|}{ Phase A } & \multicolumn{2}{c|}{ Phase B } & \multicolumn{2}{c|}{ Phase C } \\
\hline & $\begin{array}{l}\text { Mag } \\
\text { (A) }\end{array}$ & $\begin{array}{l}\text { Angle } \\
(\mathrm{deg})\end{array}$ & $\begin{array}{l}\text { Mag } \\
(\mathrm{A})\end{array}$ & $\begin{array}{l}\text { Angle } \\
(\mathrm{deg})\end{array}$ & $\begin{array}{l}\text { Mag } \\
(\mathrm{A})\end{array}$ & $\begin{array}{l}\text { Angle } \\
(\mathrm{deg})\end{array}$ \\
\hline 5 & 2.75 & 41 & 2.75 & 161 & 2.75 & 281 \\
\hline 7 & 1 & -25 & 1 & -145 & 1 & -265 \\
\hline 11 & 1.6 & 100 & 1.6 & 220 & 1.6 & 340 \\
\hline 13 & 0.2 & -75 & 0.2 & -195 & 0.2 & -315 \\
\hline
\end{tabular}

TABLE III. HARMONIC AT THE LOAD SIDE

\begin{tabular}{|l|l|l|l|l|l|l|}
\hline $\begin{array}{l}\text { Harmonic } \\
\text { order, } \mathrm{H}_{\mathrm{n}}\end{array}$ & \multicolumn{2}{|c|}{ Phase A } & \multicolumn{2}{c|}{ Phase B } & \multicolumn{2}{c|}{ Phase C } \\
\hline & $\begin{array}{l}\text { Mag } \\
\text { (A) }\end{array}$ & $\begin{array}{l}\text { Angle } \\
(\mathrm{deg})\end{array}$ & $\begin{array}{l}\text { Mag } \\
\text { (A) }\end{array}$ & $\begin{array}{l}\text { Angle } \\
\text { (deg) }\end{array}$ & $\begin{array}{l}\text { Mag } \\
(\mathrm{A})\end{array}$ & $\begin{array}{l}\text { Angle } \\
\text { (deg) }\end{array}$ \\
\hline 5 & 1.5 & 26 & 1.5 & 146 & 1.5 & 266 \\
\hline 7 & 2.3 & -15 & 2.3 & -135 & 2.3 & -255 \\
\hline 11 & 0.9 & 79 & 0.9 & 199 & 0.9 & 319 \\
\hline 13 & 0.65 & -56 & 0.65 & -176 & 0.65 & -296 \\
\hline
\end{tabular}

\section{A. Active Power Flow Method (APF)}

In the following considered case, harmonic is considered both in supply side and in load side. For each of the harmonic the active power and decision indication (dominating source of harmonic) is presented in TABLE IV.

TABLE IV. APF METHOD RESUlT

\begin{tabular}{|c|c|c|}
\hline $\begin{array}{c}\text { Harmonic } \\
\text { order, } \mathrm{H}_{\mathrm{n}}\end{array}$ & $\mathrm{P}_{\mathrm{h}}(\mathrm{W})$ & Decision (dominating harmonic source) \\
\hline 5 & 21.67 & Source \\
\hline 7 & -15.12 & Load \\
\hline 11 & 13.3 & Source \\
\hline 13 & -1.82 & Load \\
\hline
\end{tabular}




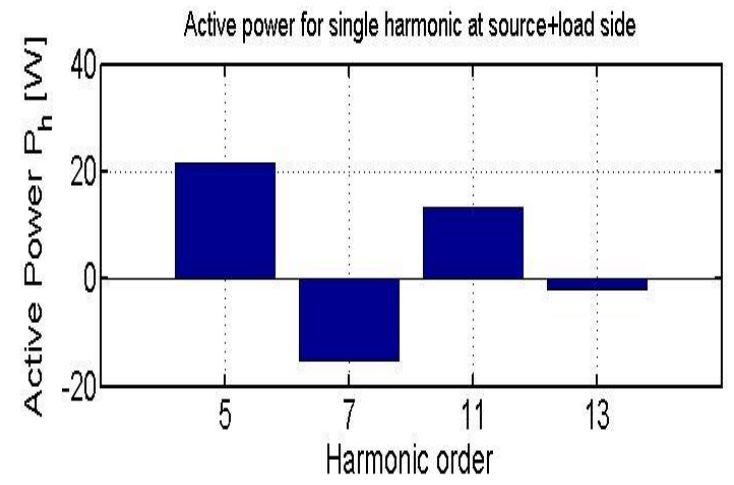

Figure 3: Harmonic order VS active power

To define the correctness of this active power flow method, a sensitivity analysis is been performed for phase change. In the simulation, harmonic source is considered in source side $\left(\mathrm{I}_{s}=\right.$ $2.75 \angle 0$ and $\mathrm{I}_{0}=1.50 \angle \Theta$ where $\Theta=0$ degree-360 degree).

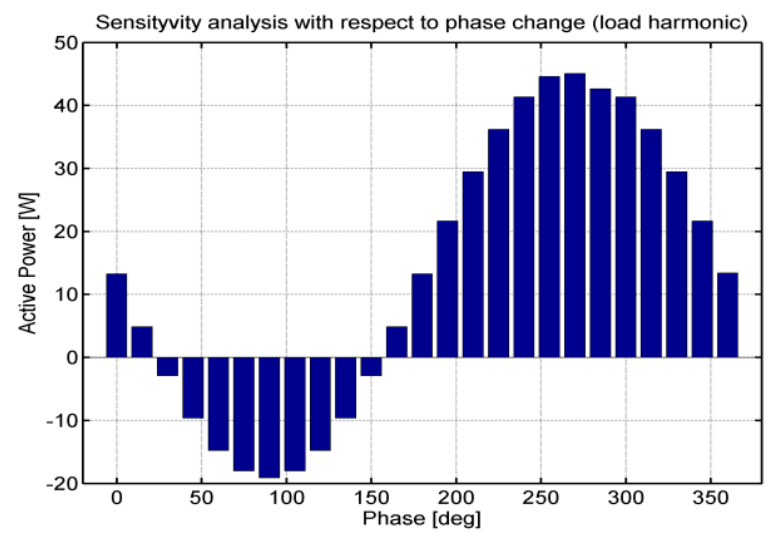

Figure 4: Sensitivity Analysis for APF method

In this graph, it is shown that from angle 30 degree to angle 150, the active power for $5^{\text {th }}$ harmonic is negative and hence it concludes the dominant source is load. But it clear that the in this condition, $\left(I_{\mathrm{s}}(2.75)>\mathrm{I}_{\mathrm{o}}(1.5 \mathrm{~A})\right)$ the source harmonic should be dominant. On the other hand, active power flow method varies with the amplitude linearly. So it can be concluded that active power flow direction method can provide erroneous result depending on the phase difference of harmonic vectors.

\section{B. Scalar Index Method}

In first case, harmonic is considered both in supply side and in load side. Then the scalar projection of current on PCC $\left(\mathrm{I}_{\mathrm{sf}}\right.$ and $\mathrm{I}_{\mathrm{of}}$ ) is calculated. From the value of scalar projection, the contribution from each side and decision is determined.

TABLE V. SI METHOD RESULT

\begin{tabular}{|c|c|c|l|}
\hline $\begin{array}{c}\text { Harmonic } \\
\text { order, } \mathrm{H}_{\mathrm{n}}\end{array}$ & $\mathrm{I}_{\mathrm{sf}}$ & \multicolumn{1}{|c|}{$\mathrm{I}_{\mathrm{of}}$} & Decision \\
\hline 5 & $1.32 \mathrm{E}+00$ & $-6.39 \mathrm{E}-01$ & Source \\
\hline 7 & $-4.77 \mathrm{E}-01$ & $1.14 \mathrm{E}+00$ & Load \\
\hline 11 & $7.38 \mathrm{E}-01$ & $-3.25 \mathrm{E}-01$ & Source \\
\hline 13 & $-8.96 \mathrm{E}-02$ & $3.22 \mathrm{E}-01$ & Load \\
\hline
\end{tabular}

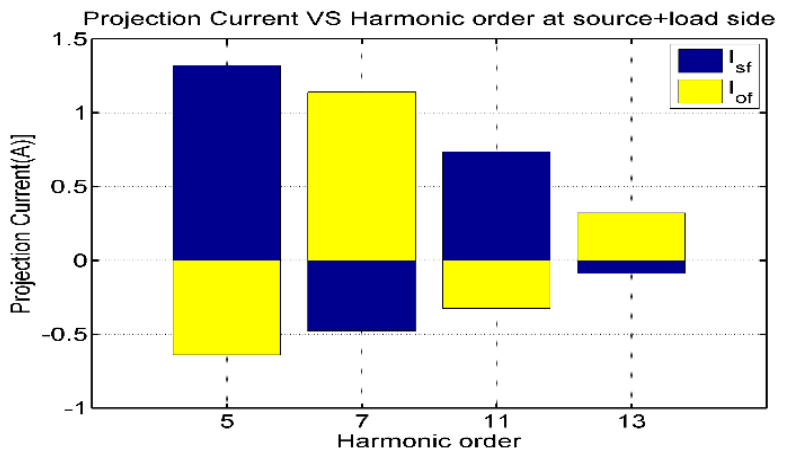

Figure 5: Harmonic order VS Projection Current

In order to define correctness of this scalar projection method, a sensitivity analysis is been performed for phase change. In the simulation, harmonic source is considered in source only.

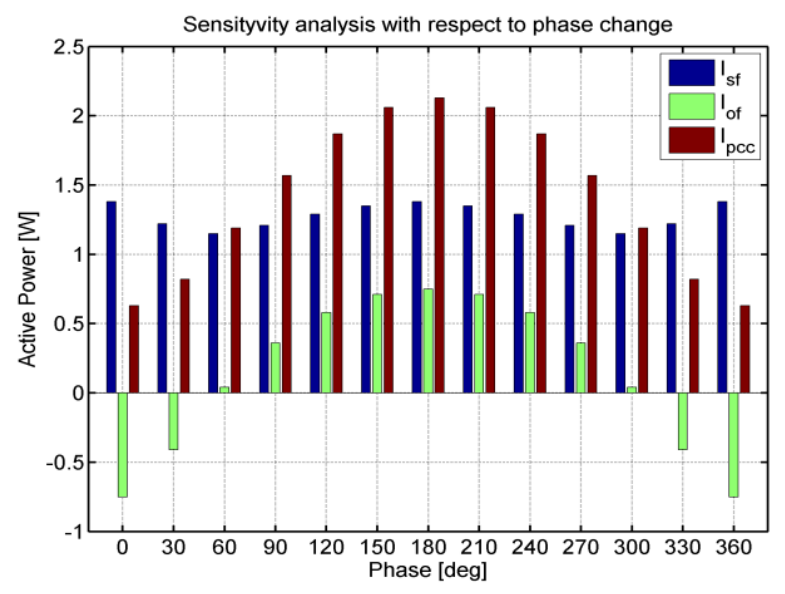

Figure 6: Sensitivity Analysis for SI method

Considered Case: $I_{s}=2.75 \angle 0$ and $I_{0}=1.50 \angle \theta$ where $\theta=0$ degree-360 degree.

From the graph, it is observed that even with the phase displacement among the current vectors, the method yield correct result as well provides contribution to PCC. So, we can conclude that the method is not affected by phase displacement and provides satisfactory result.

\section{Wilkosz Method}

Similar to SI method, Wilkosz method also requires impedance information. For simulation study and to analyze different case scenarios, the grid and consumer side impedance are selected as $10 \mathrm{ohms}$ and internal impedance of source is not been considered. As a source of harmonic distortion, current harmonic $\left(5^{\text {th }}\right)$ is considered). Harmonic is considered only supply, only load and supply and load side respectively. Then the voltage rate and current rate is calculated. From the value of these rates, the dominant source is determined. 
TABLE VI. IMPEDANCE PARAMETERS

\begin{tabular}{|l|l|l|l|}
\hline $\begin{array}{l}\text { Equivalent } \\
\text { supply side } \\
\text { Impedance, } \\
\mathrm{Z}_{\mathrm{S}}(\Omega)\end{array}$ & $\begin{array}{l}\text { Source } \\
\text { Impedance } \\
\text { Angle, } \alpha_{\mathrm{S}} \\
(\mathrm{deg})\end{array}$ & $\begin{array}{l}\text { Load } \\
\text { Impedance, } \\
\mathrm{Z}_{\mathrm{L}}(\Omega)\end{array}$ & $\begin{array}{l}\text { Load } \\
\text { Impedance } \\
\text { Angle, } \alpha_{\mathrm{L}} \\
(\mathrm{deg})\end{array}$ \\
\hline 10 & 17.43 & 10 & 17.43 \\
\hline
\end{tabular}

It should be mentioned that, since grid and load side impedance is assumed to be equal, the voltage and current rate will also be equal according the equation $\theta_{v}=\theta_{i} \frac{Z_{o}}{Z_{S}}$ [10]. All the studied case result are presented in the table VII. The investigation of sensitivity of this method within the range of impedance change along with laboratory experiment with be the future scope of this research.

TABLE VII. WILCOSZ METHOD RESULT

\begin{tabular}{|l|c|c|c|}
\hline \multicolumn{1}{|c|}{ Case } & $\begin{array}{c}\text { Current rate, } \\
\Theta_{\mathrm{i}}\end{array}$ & $\begin{array}{c}\text { Voltage rate, } \\
\Theta_{\mathrm{v}}\end{array}$ & Decision \\
\hline $\begin{array}{l}\text { Source } \\
\text { harmonic only }\end{array}$ & $1.54 \mathrm{e}-04$ & $1.54 \mathrm{e}-04$ & Source \\
\hline $\begin{array}{l}\text { Load harmonic } \\
\text { only }\end{array}$ & $6.14 \mathrm{e}+03$ & $6.14 \mathrm{e}+03$ & Load \\
\hline $\begin{array}{l}\text { Source+ load } \\
\text { harmonic }\end{array}$ & 0.54 & 0.54 & Source \\
\hline
\end{tabular}

\section{Laboratory Setup}

Different methods of identification of harmonics are also tested in laboratory environment. However, to investigate different methods specific laboratory set up is required. It should also be mentioned that the parameters for the simulation and laboratory set up is selected different because of the laboratory equipment limitation according to simulation model as well as complexity of set up. However, the authors intend to present the main base of each method and comparison among them. The active power flow method requires no impedance calculation. Other two method requires additional impedance information. For each method, Chroma Model (both source and load) is utilized. Also for other two methods ( SI Index and Wilkosz Method) additional load is connected at PCC to measure impedance of both grid and the load. A National Instrument device NI CRIO is used to measure voltage and current at PCC. Finally all the recorded data are exported to MATLAB and decision is taken according to each algorithm.

For each of the method three possible scenarios are considered: (a) harmonic only in source side; (b) harmonic only in load side and (c) harmonic on both side. In all the cases, only $5^{\text {th }}$ and $7^{\text {th }}$ harmonics have been chosen. Using Chroma, the source voltage harmonics (for $5^{\text {th }}$ and $7^{\text {th }}$ ) have been selected as $10 \%$ and $5 \%$ of the fundamental voltage respectively. For load harmonic generation, Chroma load is been employed instead of classical resistor. MATLAB/SIMULINK is used to further analysis the recorded voltage and current at PCC as well as for harmonic analysis.

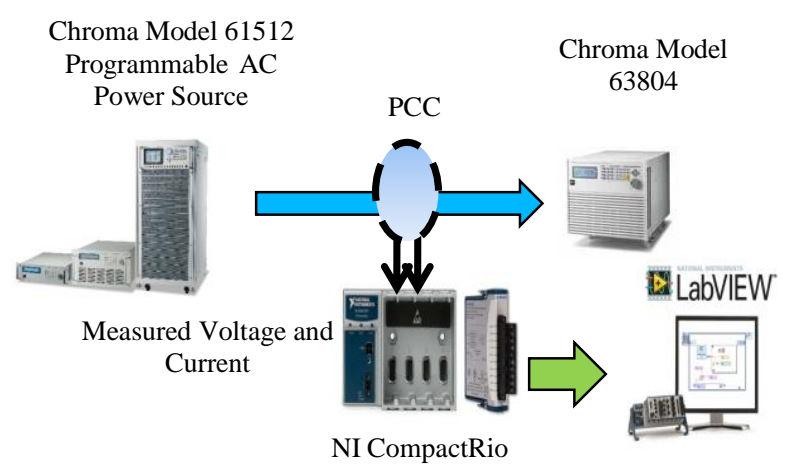

Figure 7: Laboratory setup

\section{A. Impedance Calculation set Up:}

Figure 8 shows the model of impedance calculation setup used in the experiment. In this set up, resistor coil as well well chroma load both the employed for analyzing all the case studies.

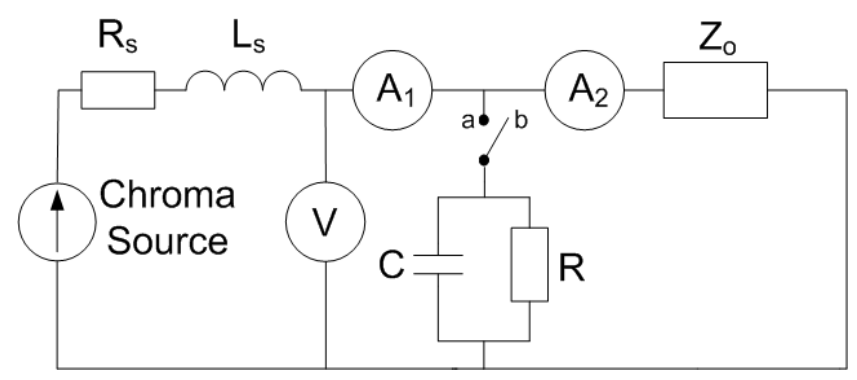

Figure 8: Model of impedance calculation laboratory setup. $\left(\mathrm{A}_{1}, \mathrm{~A}_{2}\right.$ - ampere meters, V-volt meter, $R_{\mathrm{s}}, L_{\mathrm{s}}$ - parameters of the source, $Z_{\mathrm{o}}$ - impedance of the load, $R, C$ - additional load parameters)

Currents $\mathrm{I}_{1 \mathrm{a}}, \mathrm{I}_{1 \mathrm{~b}}$ and $\mathrm{I}_{2 \mathrm{a}}, \mathrm{I}_{2 \mathrm{~b}}$ and voltage $\mathrm{V}_{\mathrm{a}}, \mathrm{V}_{\mathrm{b}}$ was measured in a configuration with and without the additional load. . Index ' $a$ ' stands for situation when switch is closed and index ' $b$ ' indicates situation when switch is opened. Currents and voltages in both configurations were sampled with the sampling frequency $F_{s}=50 \mathrm{kHz}$ within a single time frame. Such procedure ensured a proper synchronization of measured signals in both configurations. After signals measurements DFT analysis using 10 cycles of nominal frequency was performed to calculate amplitudes and phases of measured currents and voltages. Then $Z_{\mathrm{s}}$ and $Z_{\mathrm{o}}$, for 5 th and 7 th harmonic was calculated.

$$
Z_{s}=\frac{V_{b}-V_{a}}{I_{1 a}-I_{1 b}} ; Z_{o}=\frac{V_{b}-V_{a}}{I_{2 a}-I_{2 b}}
$$

Impedance of source and load for 5 th harmonic equals respectively $Z_{\mathrm{s}}=3.09+j \cdot 5.92, Z_{\mathrm{o}}=192+\mathrm{j} \cdot 28.7$, and for 7 th harmonic respectively $Z_{\mathrm{s}}=3.14+j \cdot 7.92, Z_{\mathrm{o}}=197+\mathrm{j} \cdot 26.3$. 


\section{B. Recorded wave form for case studies:}

Case study 1 (only source Harmonic): Fig. 9 represents voltage and current spectrum measured at PCC only for $5^{\text {th }}$ harmonics (only generated at source side). The harmonic component $\left(5^{\text {th }}\right)$ measured at PCC for voltage and current are $32.05 \mathrm{~V}$ and 0.16 A respectively.
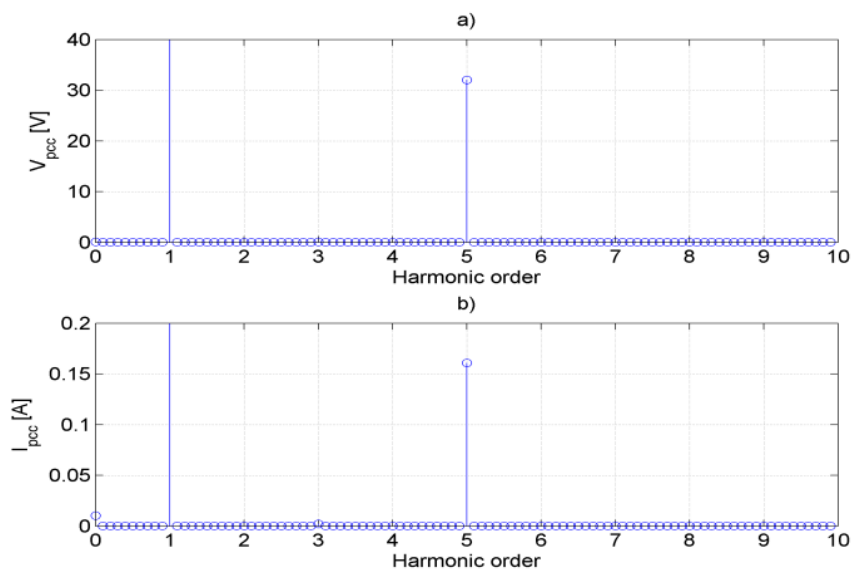

Figure 9: V and I spectrum at PCC (case study1)

Case study 2 (Only load harmonic): Fig. 10 represents voltage and current spectrum measured at PCC for $5^{\text {th }}$ and $7^{\text {th }}$ harmonics at load side (due to the nonlinearity of load). The harmonic component $\left(5^{\text {th }}\right)$ measured at PCC for voltage and current are $0.32 \mathrm{~V}$ and $0.05 \mathrm{~A}$ respectively. The voltage and current distortion are observed at PCC in much lesser portion compared with case study 1 .

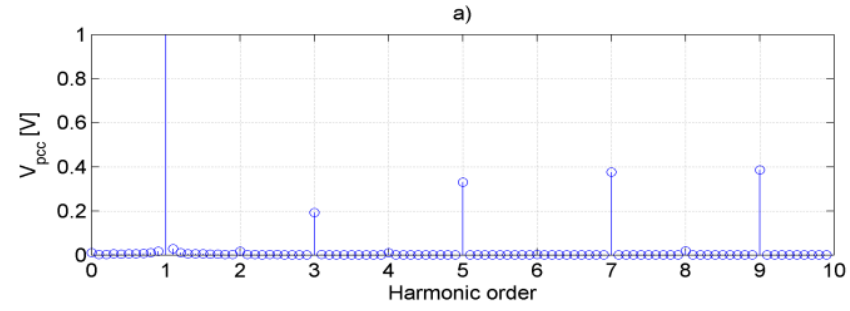

b)

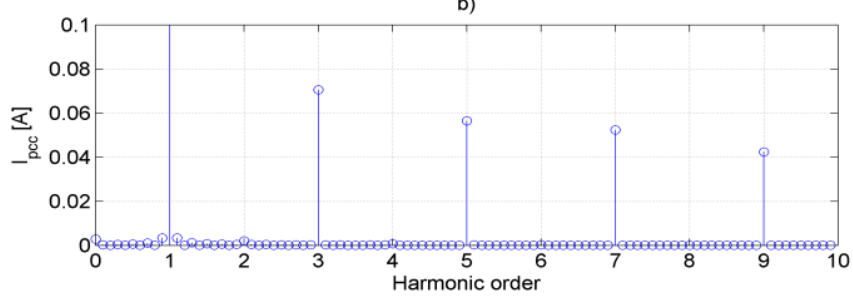

Figure10: V and I spectrum at PCC (case study 2)

Case study 3 (Both source and load harmonic): Fig. 11 represents voltage and current spectrum measured at PCC only for $5^{\text {th }}$ harmonic (10\% voltage distortion at source side and load non-linearity).
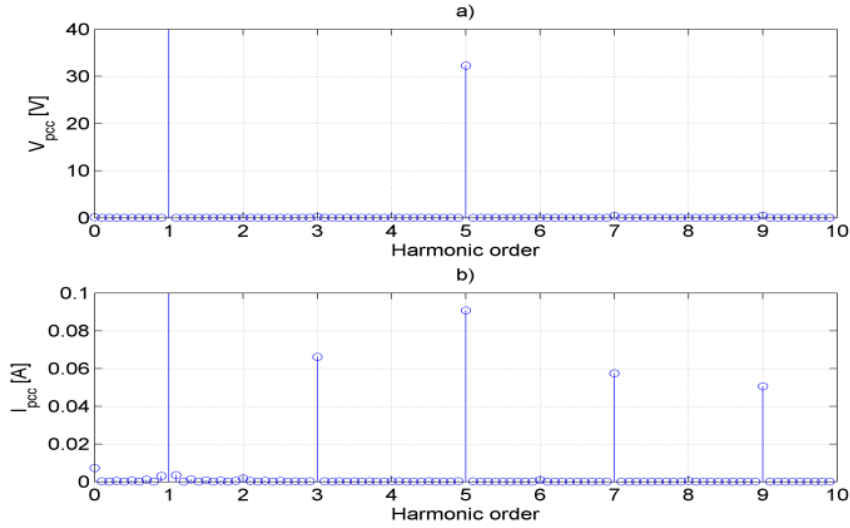

Figure 11: V and I spectrum at PCC (case study 3)

\section{Laboratory Results}

\section{A. Active Power Flow Method (APF)}

Active Power Method is been tested in the laboratory environment for all three previously described case studies. Only voltage and currents are recorded at PCC using NICRIO. The recorded waveform are analyzed using signal processing tool and active power associated for $5^{\text {th }}$ and $7^{\text {th }}$ harmonic is calculated. The harmonics are measured for 10 periods according to the standard IEC 61000-4-7 [11]. For each of the harmonic the active power and decision indication (dominating source of harmonic) is presented in TABLE VIII.

TABLE VIII. APF METHOD RESUlT

\begin{tabular}{|c|c|c|c|}
\hline Scenarios & $\begin{array}{c}\text { Harmonic } \\
\text { order, } \mathrm{H}_{\mathrm{n}}\end{array}$ & $\mathrm{P}_{\mathrm{h}}(\mathrm{W})$ & $\begin{array}{c}\text { Decision (dominating } \\
\text { harmonic source) }\end{array}$ \\
\hline $\begin{array}{c}\text { Only source } \\
\text { harmonic }\end{array}$ & 5 & 2.55 & Source \\
\cline { 2 - 4 } & 7 & 0.637 & Source \\
\hline $\begin{array}{c}\text { Only load } \\
\text { harmonic }\end{array}$ & 5 & $-4.63 \mathrm{E}-3$ & Load \\
\cline { 2 - 4 } & 7 & $-1.84 \mathrm{E}-3$ & Load \\
\hline $\begin{array}{c}\text { Both source } \\
\text { \&load } \\
\text { harmonics }\end{array}$ & 5 & 1.11 & Source \\
\cline { 2 - 4 } & 7 & 0.465 & Source \\
\hline
\end{tabular}

However, this method provides erroneous result specially in when harmonics phases change which are presented in simulation section.

\section{B. Scalar Index Method}

The primary challenge of this method is the calculation of impedance from both side. In the first step of this method, the impedance of grid and load is calculated as described in previous section. Afterwards, all three considered cases have been tested. It is also worth mentioning that this method is not affected by phase change of the corresponding harmonics. In the experiment result only the current projections are presented. The following three tables comprising result of those considered case: 
TABLE IX. SOURCE HARMONICS ONLY.

\begin{tabular}{|c|c|c|l|}
\hline $\begin{array}{l}\text { Harmonic } \\
\text { order, } \mathrm{H}_{\mathrm{n}}\end{array}$ & $\mathrm{I}_{\mathrm{sf}}$ & $\mathrm{I}_{\mathrm{of}}$ & Decision \\
\hline 5 & $1.65 \mathrm{E}-01$ & $-3.86 \mathrm{E}-03$ & Source \\
\hline 7 & $8.04 \mathrm{E}-02$ & $-5.70 \mathrm{E}-04$ & Source \\
\hline
\end{tabular}

When harmonic is considered only from source, it can be observed that the PCC contain mainly contribution from source side and $\mathrm{I}_{\mathrm{sf}}>\mathrm{I}_{\mathrm{of}}$. Also the PCC current is 0.16 (for $5^{\text {th }}$ ) and 0.07 (for $7^{\text {th }}$ ) A which justifies that the projection is correct.

TABLE X. LOAD HARMONICS ONLY

\begin{tabular}{|c|c|c|l|}
\hline $\begin{array}{l}\text { Harmonic } \\
\text { order, } \mathrm{H}_{\mathrm{n}}\end{array}$ & $\mathrm{I}_{\mathrm{sf}}$ & $\mathrm{I}_{\mathrm{of}}$ & Decision \\
\hline 5 & $7.33 \mathrm{E}-05$ & $5.64 \mathrm{E}-02$ & Load \\
\hline 7 & $4.66 \mathrm{E}-04$ & $5.18 \mathrm{E}-02$ & Load \\
\hline
\end{tabular}

In case of load harmonic only, the experiment yields $I_{\text {of }} \gg I_{s f}$ and indicates the presence of mainly load harmonics at PCC.

TABLE XI. BOTH LOAD AND SOURCE HARMONICS.

\begin{tabular}{|c|c|c|l|}
\hline $\begin{array}{l}\text { Harmonic } \\
\text { order, } \mathrm{H}_{\mathrm{n}}\end{array}$ & $\mathrm{I}_{\mathrm{sf}}$ & $\mathrm{I}_{\mathrm{of}}$ & Decision \\
\hline 5 & $1.60 \mathrm{E}-01$ & $-6.92 \mathrm{E}-02$ & Source \\
\hline 7 & $6.13 \mathrm{E}-02$ & $6.24 \mathrm{E}-03$ & Source \\
\hline
\end{tabular}

In case of both side harmonic, it is dominated by source side and the resultant of $\mathrm{I}_{\mathrm{sf}}$ and $\mathrm{I}_{\mathrm{of}}$ provides similar harmonic current component at PCC described in previous section.

\section{Wilkosz Method}

To test Wilkosz method, impedance calculated in section IV is employed. Then the recorded voltage and current were used to calculate PCC impedance and voltage and current rate are calculated. The following tables represented all three cases:

TABLE XII. WILKOSZ METHOd RESUlT - SOURCE

\begin{tabular}{|c|c|c|}
\hline Harmonic order, $\mathrm{H}_{\mathrm{n}}$ & Voltage rate, $\Theta_{\mathrm{v}}$ & Current rate, $\Theta_{\mathrm{I}}$ \\
\hline 5 & 0.02544 & 0.00087 \\
\hline 7 & 0.00989 & 0.00042 \\
\hline
\end{tabular}

TABLE XIII. WILKOSZ METHOD RESULT - LOAD

\begin{tabular}{|c|c|c|}
\hline Harmonic order, $\mathrm{H}_{\mathrm{n}}$ & Voltage rate, $\Theta_{\mathrm{v}}$ & Current rate, $\Theta_{\mathrm{I}}$ \\
\hline 5 & 217.996 & 7.49472 \\
\hline 7 & 105.727 & 4.53124 \\
\hline
\end{tabular}

TABLE XIV. WILKOSZ RESULT - SOURCE AND LOAD

\begin{tabular}{|c|c|c|}
\hline Harmonic order, $\mathrm{H}_{\mathrm{n}}$ & Voltage rate, $\Theta_{\mathrm{v}}$ & Current rate, $\Theta_{\mathrm{I}}$ \\
\hline 5 & 0.47789 & 0.01642 \\
\hline 7 & 0.64995 & 0.02785 \\
\hline
\end{tabular}

\section{Conclusion}

This paper reports three methods to locate harmonics in power system and presents different case scenarios both in SIMULINK and Laboratory environment. The current status of work leads to the conclusion of correct operation of simulation models and laboratory experiments verification for three different cases. According to the investigation, it can be mentioned that these impedance calculation based harmonic localization methods could work for high and medium voltage but this these methods could be wrong for low voltage because of nonlinearity. On the other hand, active power flow method can provide misleading information when it is subjected to phase change of harmonic component. However, the precision level of impedance based calculation largely depends on impedance calculation methods specially in non-linear cases. As a future scope of research, more sophisticated impedance calculation method will be implemented which will feature advanced signal processing methods for frequency and amplitude estimation. Also Wilkosz method will be further investigated to determine the range of impedance and thus reducing the uncertainty and complexity of calculating exact impedance information.

\section{REFERENCES}

[1] Hanzelka Z., Słupski P. Piatek K. etc. Single-point methods for location of distortion, unbalance, voltage fluctuation and dips sources in a power system, INTECH, Power Quality - modelling, analysis and enhancement, 2001, 157-1

[2] K. Vaid , Y. R. Sood and R. K. Jarial "Identification of harmonic sources in deregulated power sector", Int. J. Eng. Sci. Technol., vol. 3, no. 3, pp.2435 -2442 2011.

[3] Chun Li; Wilsun Xu; Tayjasanant, T. "A critical impedance-based method for identifying harmonic sources", Power Delivery, IEEE Transactions on, On page(s): 671 - 678 Volume: 19, Issue: 2, April 2004.

[4] Borkowski, D., "A new method for noninvasive measurement of grid harmonic impedance with data selection", Int. Trans. Electr. Energ. Syst, vol. 25 , no. 12,2015

[5] Cristaldi L, Harmonic power flow analysis for the measurement of the electric power quality, IEEE Transactions on Instrumentation and Measurement, 1995, 44(3):683-685.

[6] W. Xu, "On the validity of the power direction method of identifying harmonic source locations," IEEE Power Eng. Rev., vol. 20, pp.8-49, Jan. 2000.

[7] Wilsun Xu Yilu Liu, "A Method for Determining Customer and Utility Harmonic Contributions at the Point of Common Coupling," IEEE Trans. Power Delivery, vol. 15, pp. 804-811, Apr. 2000.

[8] Moradloo, M.; Tabrizi, M.A.; Karshenas, H.R. "A new method for identification of main harmonic source based on the superposition and critical impedance methods", Power Symposium, 2008. NAPS '08. 40th North American, On page(s): 1 - 6 .

[9] Wilkosz, K. "Single-point measurement localization of prevailing harmonic sources in a power system", Environment and Electrical Engineering (EEEIC), 2012 11th International Conference.

[10] T. Pyzalski and K. Wilkosz, "Identification of harmonic sources in a power system: a new method", IEEE PowerTech, St. Petersburg, Russia, 27-30 June 2005, pp. 1- 6.

[11] Electromagnetic compatibility (EMC) -Part 4-7: Testing and measurement techniques - General guide on harmonics and interharmonics measurements and instrumentation, for power supply systems and equipment connected thereto, IEC 61000-4-7, 2009.

[12] Matlab/Simulink User's Guide, The Mathworks Inc, 2013.

[13] National Instriments. National Instruments Website, http://www.ni.com 